\title{
Dynamic Modeling, Simulation and Optimization of a Subcritical Steam Power Plant. Part I: Plant Model and Regulatory Control
}

\author{
Chen Chen, Zhiquan Zhou, George M. Bollas* \\ Department of Chemical \& Biomolecular Engineering, University of Connecticut, 191 \\ Auditorium Road, Unit 3222, Storrs, CT 06269, USA
}

\begin{abstract}
System-level dynamic models of power plants are valuable tools for the assessment and prediction of plant performance, decisions on the design configuration, and the tuning of operating procedures and control strategies. In this work, the development of an integrated power plant model is presented. This model is validated against steady-state data from a subcritical power plant with reheat and regenerative cycles. The coal-fired power plant model studied has nominal power generation of $605 \mathrm{MW}$ and efficiency of $38.3 \%$. Traditional, regulatory control architectures are incorporated into and tuned with the dynamic power plant model. Dynamic simulation shows that the plant model is stable for sudden changes in coal load, and the controllers are able to maintain the controlled variables at their set points. In this two-part publication, we present the complete workflow of data collection, model development and validation, control tuning, dynamic optimization formulation and solution, and supervisory control architecture for a coal-fired subcritical power plant. Part I focuses on elements of model development and analysis, illustrating the advantages of acausal, objectoriented modeling in power plant simulation. Part II illustrates the use of this model for efficiency optimization under transient part-load operation.
\end{abstract}

Keywords: Power plants, control design, dynamic simulation

\footnotetext{
${ }^{*}$ Corresponding author

Email address: george.bollas@uconn.edu (George M. Bollas )
}

Preprint submitted to Energy Conversion and Management

April 14, 2017

(C) 2017. This manuscript version is made available under the Elsevier user license http://www.elsevier.com/open-access/userlicense/1.0/ 


\section{Introduction}

The main source of energy for electricity generation in power stations is fossil fuels. Coal-fired steam power plants that operate on the principle of the Rankine Cycle serve more than $1 / 3$ of the electricity demand in the U.S. to5 day [1. However, due to the need to reduce the $\mathrm{CO}_{2}$ emissions of the power generation sector [2], extensive programs have been initiated in many countries to partially replace the load of fossil fueled power plants with renewable energy resources, such as wind [3], solar [4], biomass [5], hydro [6], geothermal [7] and tidal power [8]. For instance, power generation from renewable energy sources corresponds to $\sim 20.5 \%$ of the daily power demand in the state of California 9 . It is estimated that renewable energy sources will meet $30 \%$ of power demand in 2025 and $45 \%$ of power demand in 2050 [10. Previous work has shown that an increase in renewable and distributed power generation will impact the performance and operating requirements of power plants. Edmunds et al. [11] showed that the utilization of gas power plants in the British power infrastructure will be relatively low and subject to more intense ramping operations, with increasing variable renewable penetration. The work by Wang et al. [12] illustrated potential grid stability problems in Europe, where higher penetrations of wind and photo-voltaic sources are realized. Self-regulating load control of conventional power plants is critical in the effort to adapt to the increasing penetration rates of variable renewable generation. The work by Eser et al. [13] showed that the high penetration of renewable resources in 2020 will result in a $4-23 \%$ increase of periodic start-ups of conventional power plants, and a $63-181 \%$ increase of load ramps. Transient operation of conventional power plants will become necessary to balance the grid load. Meanwhile, due to the increasing safety and environmental regulations, as well as the daily fluctuations in electricity demand, power plants will be (and are) subject to frequent load changes or partial shutdowns.

Physics-based power plant models can play a substantial role in the design of steam power plant configurations, performance analysis, design of control strate- 
gies, optimization of system operation, and maintenance. Specifically, plant simulators allow operators to test normal, off-design, transient, emergency, and unconventional operating procedures. On a first level, steady-state modeling is commonly used to design and analyze the integrated power plant or its components. For example, Pei et al. [14] simulated oxyfuel combustion at steady state 35 in a $300 \mathrm{MW}$ pulverized coal-fired plant, using Aspen Plus. They studied and optimized the impact of different mixing percentages of $\mathrm{O}_{2} / \mathrm{CO}_{2}$, on the combustor flue gas. Sahin et al. [15] presented gas turbine models of combined cycle power plants for exergo-economic analysis. The size and configuration of power plants were shown to depend mainly on the levelized cost of electricity, exergy 40 efficiency, or total cost of investment. Zare and Hasanzadeh [16 developed a steady state model of a closed Brayton cycle-based solar power plant, showing that efficiency improvements of up to $30 \%$ can be achieved by optimizing gas turbine inlet temperature, evaporator temperature, compressor pressure ratio and heliostat field efficiency. Peng et al. 17. presented a steady state model 45 of a $330 \mathrm{MW}$ hybrid solar/coal-fired power plant, which they used for exergy evaluation. Their simulation results indicated that the hybrid power plant has lower exergy destruction than the solar-only thermal power plant. Zhou et al. [18] evaluated power plant efficiency by modeling a $1000 \mathrm{MW}$ dual reheat ultrasupercritical power plant. They showed that a power plant with ten stages of 50 steam extraction has higher efficiency than a equivalent plant with eight stages. Kumar et al. [19] presented steady state models of subcritical (550 MW), supercritical (660 MW) and ultra-supercritical (800 MW) coal-fired power plants. Their analysis showed that increasing the main steam temperature allows reduction of the auxiliary power consumption and coal consumption. Kakaras et al.

55 20] developed a steady-state model of a $300 \mathrm{MW}$ coal-fired supercritical power plant, to estimate the efficiency and power generation of an oxyfuel lignite-fired power plant. Their analysis showed that the application of oxyfuel $\mathrm{CO}_{2}$ capture encompasses an efficiency penalty of $8.5 \%$, with the oxyfuel heat exchangers requiring lower boiler investment than conventional coal-fired power plants.

More recent efforts have focused on dynamic simulation to evaluate the tran- 
sient operation of power plants, the sizing of equipment and control design. In this context, Colonna and Putten [21,22] developed a power plant model in the software SimECS, and the model was validated by comparison with a lab-scale biomass-fired steam cycle power plant operating at steady state and dynamically. Casella et al. [23, 24] developed models for the dynamic simulation of Organic Rankine Cycles (ORC) and Integrated Gasification Combined Cycles (IGCC), using the Modelica language [25] and component models from the ThermalPower library [26. Chen et al. 27] developed a system-level dynamic model of a combined cycle power plant integrated with chemical-looping combustion and the model was validated at steady-state against commercial plant data. Wang et al. 28] presented work on parametric optimization of supercritical coal-fired power plants. They showed that the optimal pressure ratios of reheating streams were $0.15-0.3$, and a decrease of $2 \%$ in cost of electricity is feasible. Bhambare et al. 29] modeled a natural circulation boiler of 75 a coal-fired thermal power station. They presented open-loop responses of a dynamic model to step changes in operating parameters, with the dynamic simulator showing good agreement with the actual power plant. Starkloff et al. [30] presented a detailed dynamic model of a $750 \mathrm{MW}$ coal-fired power plant and validated the model against steady-state data from a power plant located 80 in Germany. Their dynamic simulation results were consistent with the plant measurements for load changes of $\pm 27.5 \%$. Power plant models in modern simulation environments have also been explored by several power plant providers, such as ABB [31], EDF [32], and Siemens [33]. Dynamic models are noted to enable development of real-time optimization algorithms for power plant efficiency improvement and emissions reduction.

As the variations of power demand or shut-downs become increasingly frequent, plant control requirements become more challenging. Different control designs and architectures are implemented in power plants to keep up with the challenges in infrastructure brought by the need for variable load operation. Research has focused on implementing advanced control strategies in power plants has drawn attention. For instance, Wang et al. 34] proposed a control design for 
power systems to rapidly increase excitation and decrease the turbine mechanical input when a fault occurs, and enhance transient stability and the regulation of the generator terminal voltage. Pan et al. 35] presented an adaptive proportional and integral controller using only the available information of model states and outputs of model and plant. This controller was used for load-frequency control of power systems without explicit parameters. Ben-Abdennourt et al. [36. presented a power plant nonlinear model with decentralized control strategy for the boiler turbines, and a power stabilizing control scheme for the generator. Alobaid et al. 37, 38 presented a control architecture for a combined cycle power plant during warm start-up, based on models developed in software Apros and Aspen Plus Dynamics. They showed that the drum levels and the feedwater mass flow rate can be simulated and controlled with higher accuracy, than the mass flow rate, temperature and pressure of steam. Overall, research so far has focused on stability and efficiency improvements through advanced control.

Given that subcritical power plants are the most common configuration and will remain so in the next decades, research on the dynamic simulation, optimization and control of subcritical power plants is of interest. Despite significant progress in the dynamic simulation of novel thermal power plants 39, only few dynamic models of coal-fired power plants have been presented in the open literature. Moreover, these models are not available publicly, for researchers to use then as testbeds for further analysis. In this work, a high-fidelity dynamic model with minimum boundary parameterization was developed on the basis of a 605 MW coal-fired, subcritical-pressure, power plant with regenerative reheat cycle. The model was validated against steady-state data from a fossil-fueled power plant reported in the literature 40. Conventional regulatory controllers were incorporated in the plant model, and the control tuning is discussed. The responses of the most important performance and stability variables during transient load operation are presented. In Section 2, the configuration, design and control architecture of the power plant studied are presented. In Section 3, the development of the plant model is discussed, and all the relevant plant input 
data and parameters are provided. In Section 4, the validation of the model, quantitatively at steady state and qualitatively in dynamic operation is presented. All the model parameters are provided in the Appendix and the entire power plant model is available in the Supporting Information of this paper.

\section{Configuration of the fossil-fueled subcritical power plant studied}

A simple diagram of the fossil fuel-fired subcritical power plant simulated in this work is shown in Figure 1 [40. The simulated plant corresponds to a $605 \mathrm{MW}$ fossil-fueled reheat cycle designed for nominal turbine conditions of 174 bar and $538^{\circ} \mathrm{C}$ steam. Operating conditions for this plant at full load and steady state were reported by Singer 40. Accordingly, this plant was first simulated with mass flows corresponding to full-load operation. In the plant described in detail in Singer [40, fossil fuel is burnt in the combustor to produce hot flue gas. As shown in Figure 1 the heat of the flue gas is used to convert the feedwater to high temperature dry steam, through a series of heat exchange steps in the boiler, including the Economizer, Evaporator and Reheater, and Superheater steps. The superheated steam produced in the boiler is expanded in high-pressure (HP), intermediate-pressure (IP), and low-pressure (LP) turbines connected to a generator to produce electricity. Four feedwater heat exchange steps, including a deaerator and three heat exchangers, are supplied with steam streams extracted from the multi-stage turbines. Three pumps are used for circulating the water after being condensed in the condenser. The preheated condensate re-enters the boiler at high pressure and closes the loop. A reheat cycle is used to reduce the irreversibility of the process, by increasing the turbine inlet temperature and reheating the working steam after expansion in the turbines. The two main sections of this plant, boiler and steam side are discussed in detail in the following. 


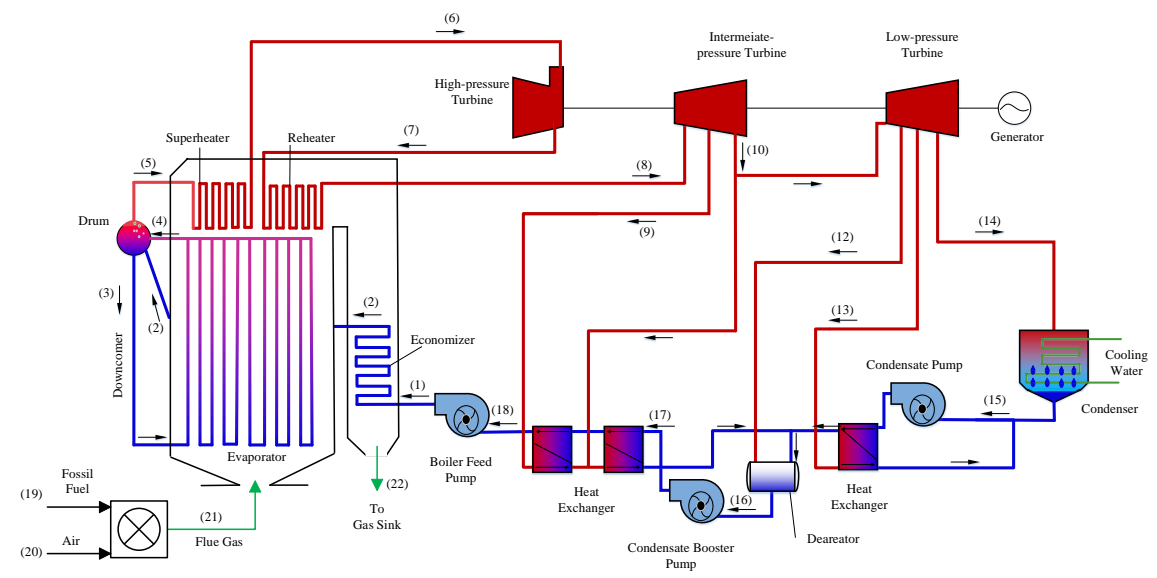

Figure 1: The reheat, regenerative-cycle, $605 \mathrm{MW}$ subcritical-pressure fossil power plant studied in this work [40].

\subsection{Boiler}

The boiler converts the feedwater to superheated steam and reheats the steam after expansion in the high-pressure turbine. As shown in Figure 2. the subcritical-pressure boiler is composed of the following subsystems: Drum, Downcomer, Economizer, Evaporator, Reheater, and Superheater. Compared to other types of water tube boilers, the steam drum boiler studied in this work has better tolerance to impurities and lower internal consumption of electricity [41, 42]. The water and flue gas flow paths in the boiler are shown in Figure 2 . where the blue solid line denotes the water cycle, and the red dashed line denotes the flue gas stream. In the boiler, two interacting fluid circuits exchange heat; namely, the flue gas circuit and the water circuit. The flue gas circuit starts with the oxidation of fossil fuel with air in the combustor. The combustion gas flows through the Evaporator, Superheater, Reheater and Economizer, successively. In these heat exchange steps, the heat of the flue gas is transferred to the water circuit coils. In the water circuit, the high-pressure feedwater first flows through the Economizer and gets preheated to a temperature $15-30^{\circ} \mathrm{C}$ lower than its boiling point [42. The preheated feedwater is collected in a steam drum and then flows to the Evaporator via the Downcomer. The Downcomer 
is a set of pipes situated outside the furnace to prevent the water exiting the Drum from evaporating and provide the driving force for natural circulation. The water is partially converted to steam in the Evaporator tubes and the liquidvapor mixture returns to the Drum. The subcritical-pressure drum separates the steam from the mixture and reduces its moisture. To increase the temperature, reduce the moisture and improve thermal efficiency, the steam flows to the Superheater, exploiting the heat of the flue gas. The Reheater is used to protect the subsequent turbines from being damaged by excessive moisture, by re-superheating the steam after being expanded in the HP turbine [40].

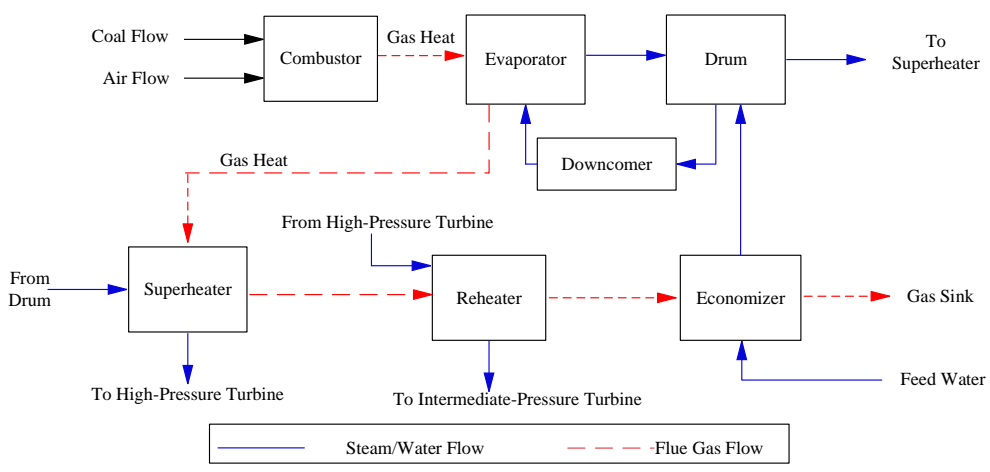

Figure 2: Simplified diagram of the boiler system of the $605 \mathrm{MW}$ subcritical-pressure coal-fired power plant studied in this work.

\subsection{Steam side}

The steam cycle converts the heat of the hot and high-pressure steam to mechanical power and electricity, and pressurizes the preheat condensate. A simplified diagram of the thermal cycle of the power plant studied is shown in Figure 3. The high-pressure, dry steam produced in the boiler is expanded through multi-stage turbines connected to an electric generator. In the multistage expansion process, the steam heat is converted to mechanical torque. After being expanded in the HP turbine, the steam is re-superheated in the boiler to improve plant efficiency. The steam exiting the LP turbine is condensed to liquid in the condenser, fed with cooling water. The condensate is preheated 
by the heat of the steam extracted from the turbines in the feedwater heat exchangers, before entering the boiler. A deaerator heater is used to remove oxygen and other dissolved gases from the feedwater. This regenerative heating process transfers heat from one part of the cycle to another to reduce external irreversibility. Three pumps are used to drive the condensate through four heat exchangers. The condensate pump (CP) pressurizes the condensate through the 1 st heat exchanger and deaerator (2nd heat exchanger). The CP drives the condensate through the 3rd and 4th heat exchangers. Finally, the boiler feed pump (BPF) pressurizes the condensate back to the boiler to close the loop.

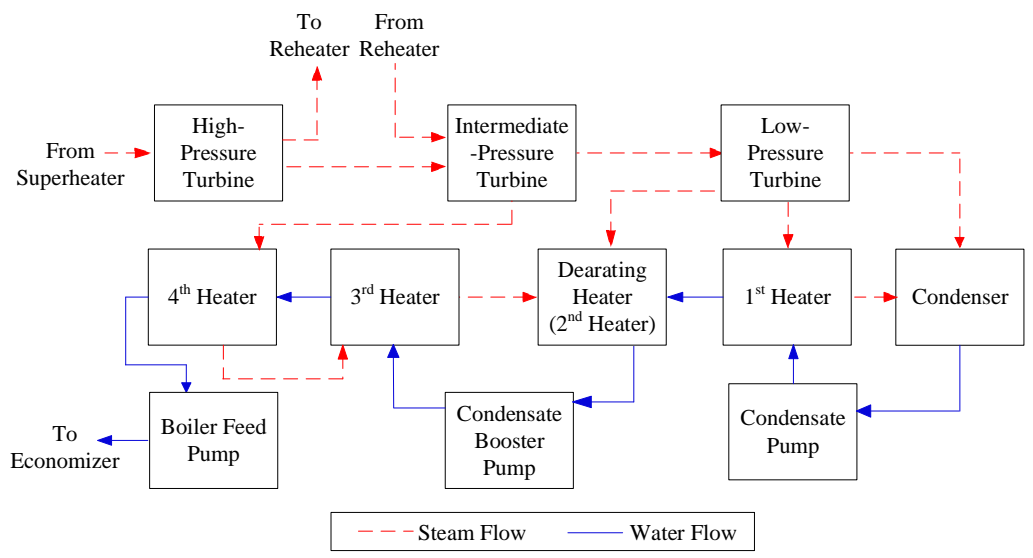

Figure 3: Simplified diagram of the steam side system of the 605 MW subcritical-pressure coal-fired power plant studied in this work.

\subsection{Control structure}

In order to maintain power plant stability and regulate the power plant, necessary consideration was taken for the inclusion of regulatory control loops in the plant. In the plant description by Singer [40, only the open-loop configuration is presented (for design analyses). Therefore, common power plant control configurations [43, 44] were used in this work, which enabled the study of the closed-loop performance of the plant, as well as the analysis of benefits of supervisory control (based on set-point optimization) presented in Part II of this work [45]. Basic control logic to serve the requirements for dynamic per- 
formance and stability at varying control loads was incorporated in the power plant in the form of regulatory controllers, tuned to match information available about the reference power plant. This regulatory control architecture included controllers for coal and air mass flow rates, pump speeds and valve openings, and is discussed in detail in the following.

For the boiler subsystem, the regulatory control structure includes Proportional - Integral - Derivative (PID) controllers for the Drum level and steam temperature control, as shown in Figure 4. The Drum level controller manipulates the speed of BFP to keep the liquid level of the Drum at half height, by adjusting the mass flow of the feedwater to the Economizer. The Drum level is measured with a level sensor and the set point was set to $0 \mathrm{~m}$ with the actuator being the speed of the BFP. A reverse action controller was used for the superheated steam temperature $\left(T_{\mathrm{SH}}\right)$ control, using spray attemporators. This tunes the mass flow of feedwater that is mixed with the superheated steam by manipulating the feedwater valve opening, to control the temperature of the steam exiting the Superheater at $538^{\circ} \mathrm{C}$. For the temperature controller, the measurement is $T_{\mathrm{SH}}$, the set point is $538^{\circ} \mathrm{C}$, and the actuator is the opening of the feedwater valve, as shown in Figure 4. In the combustor, the controller of the air mass flow rate was used to regulate the excess oxygen to ensure nearcomplete combustion. The control architecture measures the mass fraction of oxygen in the flue gas exiting the boiler, with set point at $3 \%$, and manipulates the mass flow rate, as shown in Figure 4 . The selection of $3 \%$ oxygen in the flue gas is in accordance with the excess oxygen conventionally used in steam power plants with air combustion boilers [46]. 

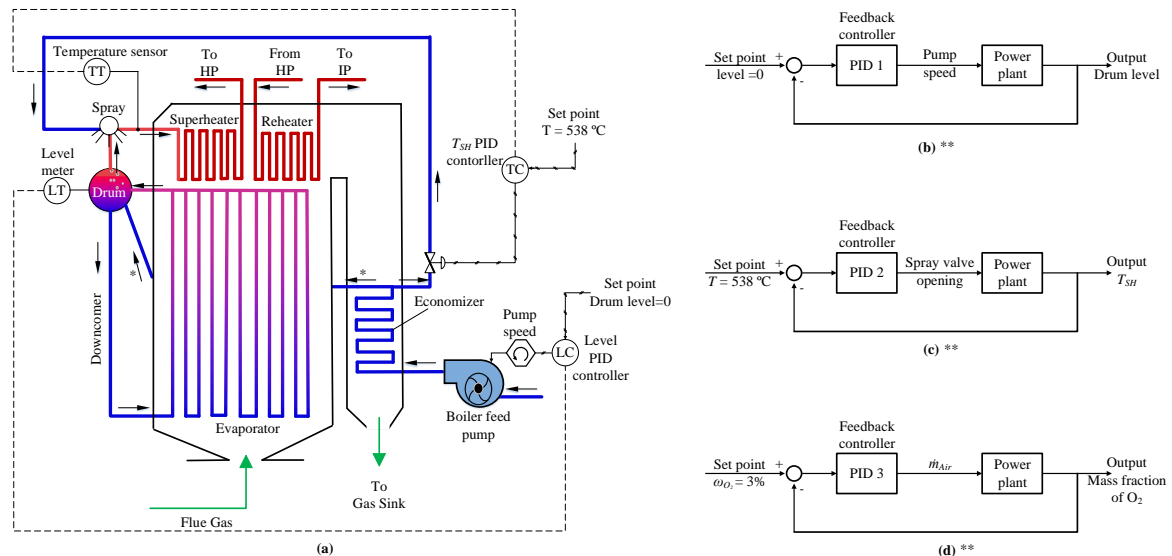

Figure 4: (a) simplified diagram of the boiler with its control design, (b) drum level controller, (c) superheated steam temperature controller, (d) air mass flow rate controller.

* Same stream, **model parameters of PID controllers as shown in Table 5

For the steam side subsystem, the control architecture incorporated is shown in Figure 5. The speed of the condensate pump is controlled by the condenser level controller to prevent the condenser from running empty and drive the condensate through the 1st feedwater heat exchanger and deaerator (2nd heat exchanger). In the condenser level control structure, the measurement is the liquid level of the condenser, the set point was set to $0.4 \mathrm{~m}$, and the actuator is the speed of the condenser pump. The speed of the condensate booster pump $(\mathrm{CBP})$ is manipulated with input from the deaerator level controller to keep the liquid in the deaerator at a constant level and drive the condensate through the 3rd and 4th heat exchangers. In the deaerator level controller, the measurement is the liquid level of the deaerator, the set point is $0 \mathrm{~m}$, and the actuator is the speed of the CBP. These controllers were tuned using step responses, as discussed in the following. 


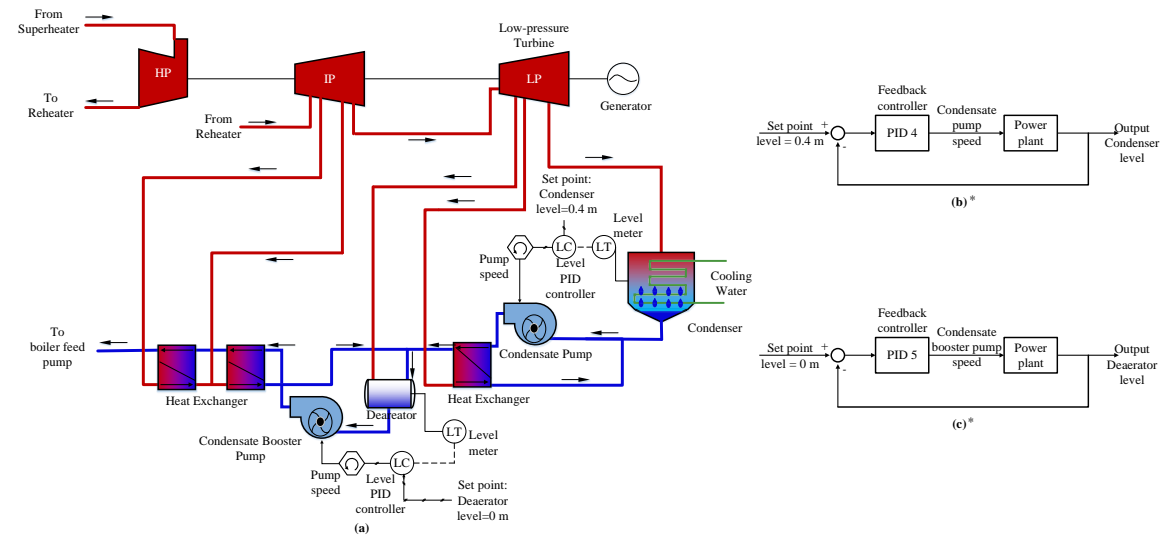

Figure 5: (a) simplified diagram of the steam side system with its control design, (b) controller for the condenser level, (c) controller for the deaerator level.

*Model parameters of PID controllers as shown in Table 5

\section{Description of subcritical power plant model}

The plant of Figure 1 was simulated with a dynamic power plant model developed in Dymola [47] using the Modelon ThermalPower library [26], as shown in Figure6. The Modelica language used in Dymola is a non-proprietary, objectoriented, and equation-based language for the modeling of complex physical systems. We chose the Modelica language for this simulation, in particular Dymola, because of its acausal structure and extensive libraries of components relevant to thermal cycles. In the past, the ThermalPower library of Dymola has been used to dynamically simulate ORC [24], IGCC [23], and CC-CLC plants [27]. The reference plant, as described in Section 2, was simulated as an integrated model of boiler and steam side. A comprehensive list of the operating data of the power plant model is provided in the Appendix and the Supporting Information of this document. In the following, the main attributes of the model are discussed, along with the steady-state validation of the model developed. 


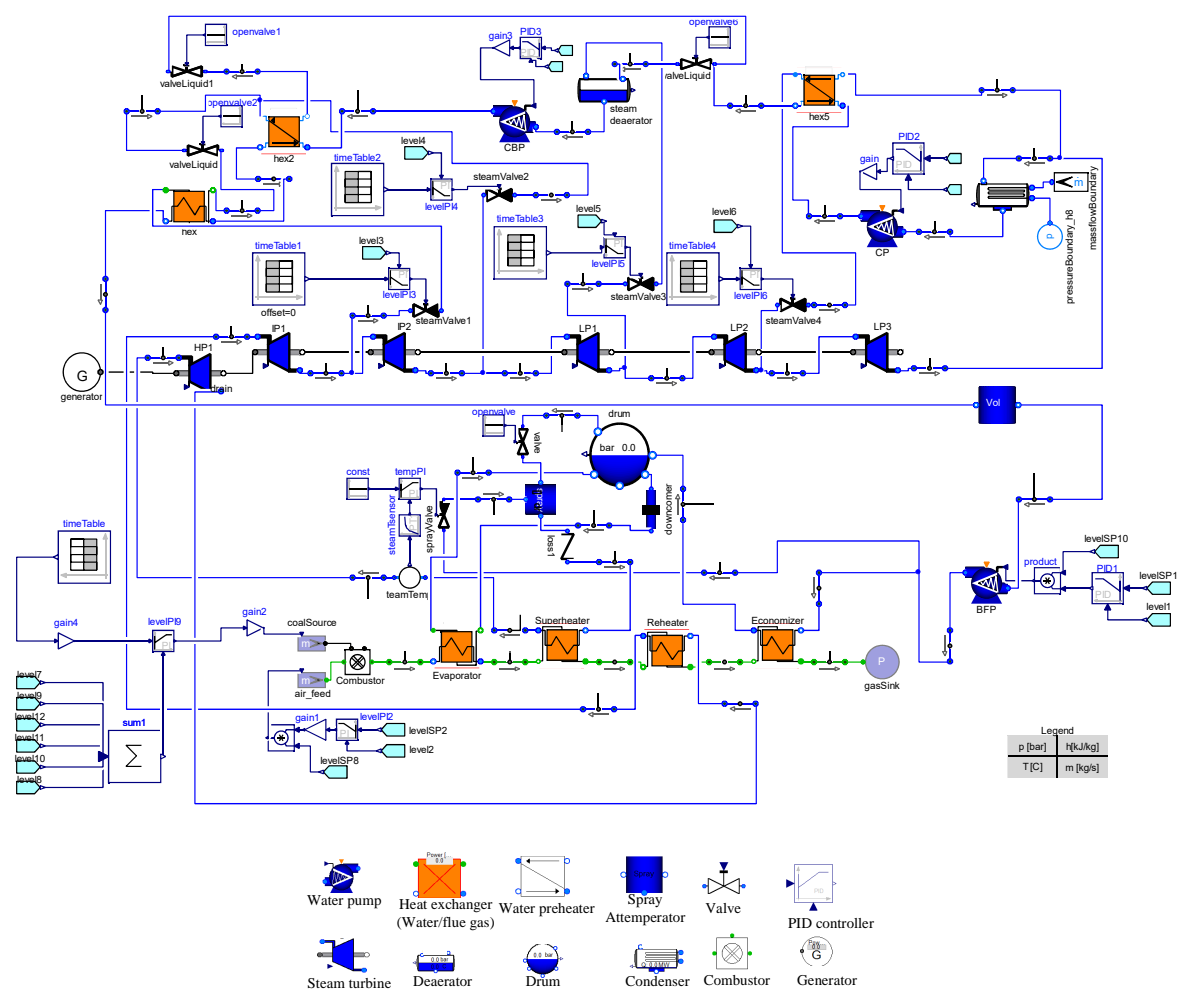

Figure 6: Diagram of the $605 \mathrm{MW}$ coal-fired subcritical power plant model, developed in Dymola [47.

\subsection{Boiler model}

The tubing and piping of the boiler in the plant were simulated as a series of shell and tube heat exchangers, representing the Evaporator, Superheater, Reheater, and Economizer. This approximation is consistent with the arrangement of the piping inside the boiler and is common practice in Rankine Cycle simulation [40, 42, 48, For each heat exchanger, the size and heat transfer coefficients were tuned to match the pressure drop through tubing and exit temperatures of the plant reported in Singer [40]. The generated superheated steam is at 173.7 bar and $538^{\circ} \mathrm{C}$, and the mass flow rate is $490 \mathrm{~kg} / \mathrm{s}$. In order to improve efficiency, the steam is also re-superheated to a temperature of $538^{\circ} \mathrm{C}$ in the

Reheater block. The typical circulation ratio around the evaporator is 5-100 for 
natural circulation boilers 42 . In this work, a circulation ratio $\sim 5$ was chosen, with the water circulating through the evaporator set to $\sim 2500 \mathrm{~kg} / \mathrm{s}$. According to the design of heat exchangers in the boiler [42, the pressure loss of water in the Economizer, Superheater and Reheater was set to 5-10\%, less than $10 \%$ and $\sim 5 \%$, respectively. The coal mass flow rate used in the base-case simulation was $56.38 \mathrm{~kg} / \mathrm{s}$. The preheat temperature of incoming air was $200^{\circ} \mathrm{C}$ and the gas exits the Economizer heat exchangers approximately at 1 bar [49]. Based on data from industrial manufacturers [50, 51, 52] and previous work [53, 48, 40], the configuration and initial inputs of the Drum, Downcomer and Spray Attemprator were specified, as shown in Table 1. The level of water in the Drum is reported as an offset from the half height (positive or negative).

Table 1: Boiler parameters.

\begin{tabular}{|c|c|c|c|}
\hline \multicolumn{4}{|c|}{ Drum } \\
\hline Internal radius $[\mathrm{m}]$ & 1 & Initial pressure [bar] & 180 \\
\hline External radius $[\mathrm{m}]$ & 1.1 & Water initial height $[\mathrm{m}]$ & 0 \\
\hline Length $[\mathrm{m}]$ & 15 & Wall temperature $\left[{ }^{\circ} \mathrm{C}\right]$ & 380 \\
\hline Orientation & Horizontal & Water phase & Liquid/vapor \\
\hline \multicolumn{2}{|l|}{ Downcomer } & \multicolumn{2}{|c|}{ Spray Attemperator } \\
\hline Height $[\mathrm{m}]$ & 20 & Total Volume $\left[\mathrm{m}^{3}\right]$ & 0.1 \\
\hline Nominal flow $[\mathrm{kg} / \mathrm{s}]$ & 2500 & Nominal flow $[\mathrm{kg} / \mathrm{s}]$ & 490 \\
\hline Nominal pressure [bar] & 180 & Initial pressure [bar] & 180 \\
\hline Nominal temperature $\left[{ }^{\circ} \mathrm{C}\right]$ & 380 & Initial temperature $\left[{ }^{\circ} \mathrm{C}\right]$ & 380 \\
\hline
\end{tabular}

\subsection{Steam side model}

The heat of the high-pressure and superheated steam is converted to mechanical work, in the HP, IP and LP turbines, which are connected to a power generator. For the purpose of steam cycle simulation, each turbine was split into cascade sections [40]. A generator model with a constant efficiency of 0.99 was used for simulating power generation. The power generated by this plant arrangement of steam turbines was $605 \mathrm{MW}$ and the nominal plant efficiency was calculated at $38.3 \%$. The condenser was sized to condense the steam at 0.05 
the following.

Table 2: Steam side parameters.

\begin{tabular}{|l|l||l|l|}
\hline \multicolumn{4}{|c|}{ Condenser } \\
\hline Diameter [m] & 2 & Initial pressure [bar] & 0.068 \\
\hline Length [m] & 10 & Water initial height $[\mathrm{m}]$ & 0.4 \\
\hline Orientation & Horizontal & Wall temperature $\left[{ }^{\circ} \mathrm{C}\right]$ & 38.5 \\
\hline \hline
\end{tabular}

\begin{tabular}{|l|l||l|l|}
\hline \hline \multicolumn{3}{|c|}{ Deaerator } \\
\hline Internal radius [m] & 2.5 & Initial pressure [bar] & 4.4 \\
\hline External radius [m] & 2.6 & Water initial height $[\mathrm{m}]$ & 0 \\
\hline Length [m] & 10 & Wall temperature $\left[{ }^{\circ} \mathrm{C}\right]$ & 120 \\
\hline Orientation & Horizontal & Water phase & Liquid/vapor \\
\hline
\end{tabular}

\section{Model validation and verification}

\subsection{Steady-state validation}

Table 3 reports the steady-state model of selected flows with the order and notation as presented in Figure 1. The steady-state instance of the plant model was tuned to match the performance of the $605 \mathrm{MW}$ fossil fuel plant reported by Singer [40. The comparison of the reference power plant data with the corresponding predictions from the plant model is shown in Table 4 . The power 
of $605 \mathrm{MW}$ generated by the subcritical plant model is in excellent agreement

ied power plant, such as the water flow rate, turbine operating pressures and temperatures. The net power efficiency of $38.3 \%$ is consistent with the average efficiency of coal-fired subcritical power plants reported in the literature [49, 54]. The condenser operating pressure predicted by the model is slightly lower than Figure 7 shows the comparison of the prediction of the integrated plant and the data reported in the literature [40, 42, in terms of temperature and pressure. Due to the heat transfer between water and flue gas in the boiler, the water temperature increases from $200^{\circ} \mathrm{C}$ at the Economizer inlet to $538^{\circ} \mathrm{C}$ at the Superheater outlet. This heat transfer is accurately captured in the model, as indicated by the temperature predictions in process points 1-6. The pressure loss in the boiler tubing and piping is also in excellent agreement with the plant data, shown in process points 1-6 in Figure 7(b). The expansion of the high temperature and pressure steam in the HP, IP and LP turbines is accurately modeled as shown in process points 6-7 and 8-13 in Figure 7. After the expansion in the HP turbine, the steam is sent back to the Reheater block in the boiler and is re-superheated to $538^{\circ} \mathrm{C}$, as shown in process points $7-8$. The phase change from steam to liquid in the condenser is predicted to occur at $38^{\circ} \mathrm{C}$ and 0.05 bar, shown as process point 13. The compression and preheating in points 12-13 and 14-17 of Figure 7] depicting the increase of temperature and pressure of the condensate. In summary, the proposed model is satisfactory and reliable in terms of reproducing the reported reference power plant operating data at full load. 
Table 3: Selected streams of the coal-fired subcritical power plant model [40, 42, 49].

\begin{tabular}{|c|c|c|c|c|}
\hline Stream No.* & Medium & $P[\mathrm{bar}]$ & $T\left[{ }^{\circ} \mathrm{C}\right]$ & $\dot{m}[\mathrm{~kg} / \mathrm{s}]$ \\
\hline 1 & Water (l) & 199 & 188 & 502 \\
\hline 2 & Water (l) & 179 & 324 & 502 \\
\hline 3 & Water (l) & 180.57 & 352 & 502 \\
\hline 4 & Water $(\mathrm{l} / \mathrm{g})$ & 179 & 357 & 502 \\
\hline 5 & Water (g) & 179 & 357 & 502 \\
\hline 6 & Water (g) & 170 & 538 & 502 \\
\hline 7 & Water (g) & 45 & 347.2 & 502 \\
\hline 8 & Water (g) & 39.35 & 533.5 & 502 \\
\hline 9 & Water (g) & 24.67 & 465.8 & 27.4 \\
\hline 10 & Water (g) & 12.7 & 377 & 14 \\
\hline 11 & Water (g) & 7.94 & 304.6 & 462.5 \\
\hline 12 & Water (g) & 4.7 & 244 & 16.5 \\
\hline 13 & Water $(\mathrm{g})$ & 1.76 & 144.7 & 30 \\
\hline 14 & Water (g) & 0.068 & 34 & 396 \\
\hline 15 & Water (l) & 0.068 & 90.4 & 396 \\
\hline 16 & Water (1) & 2.3 & 127.2 & 502 \\
\hline 17 & Water (l) & 13 & 153.1 & 502 \\
\hline 18 & Water (l) & 11 & 183.5 & 502 \\
\hline 19 & Coal (s) & 1.01 & 27 & 56.38 \\
\hline 20 & Air (g) & 1.01 & 200 & 627 \\
\hline 21 & Flue gas (g) & 1.01 & 2037 & 683 \\
\hline 22 & Flue gas (g) & 1 & 270 & 683 \\
\hline
\end{tabular}

* Stream No. corresponds to the process arrangement and ordering shown in Figure

11 
Table 4: Comparison of reference power plant 40 and plant model.

\begin{tabular}{|l|l|l|}
\hline Subcritical Power plant & Reference plant & Plant model \\
\hline \hline Fuel & Fossil fuel & Coal \\
\hline Fuel flow rate $[\mathrm{kg} / \mathrm{s}]$ & - & 56.38 \\
\hline Water flow rate $[\mathrm{kg} / \mathrm{s}]$ & 514.1 & 502 \\
\hline HP operating pressure $[\mathrm{bar}]$ & 173.7 & 170 \\
\hline IP operating pressure $[\mathrm{bar}]$ & 40.5 & 39.35 \\
\hline LP operating pressure $[\mathrm{bar}]$ & 12.1 & 12.7 \\
\hline HP Temperature $\left[{ }^{\circ} \mathrm{C}\right]$ & 538 & 538 \\
\hline IP Temperature $\left[{ }^{\circ} \mathrm{C}\right]$ & 538 & 533.5 \\
\hline LP Temperature $\left[{ }^{\circ} \mathrm{C}\right]$ & 378 & 377 \\
\hline Condenser pressure $[\mathrm{bar}]$ & 0.068 & 0.05 \\
\hline Power $[$ MW $]$ & 608 & 605.4 \\
\hline Net efficiency $[\%]$ & - & 38.3 \\
\hline
\end{tabular}




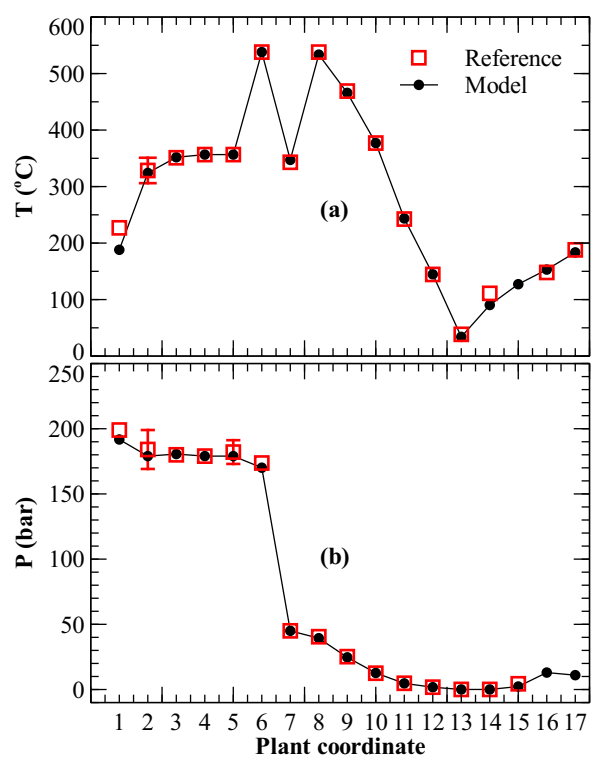

Figure 7: Comparison of the prediction of the integrated plant and the data reported in [40, 42] in terms of the system temperature and pressure. (1: Economizer inlet; 2: Economizer outlet; 3: Evaporator inlet; 4: Evaporator outlet; 5: Superheater inlet; 6: Superheater outlet; 7: HP Turbine outlet; 8: Reheater outlet; 9: IP1 Turbine outlet; 10: IP2 Turbine outlet; 11: LP1 Turbine outlet; 12: LP2 Turbine outlet; 13: LP3 Turbine outlet; 14: CP outlet; 15: Deaerator outlet; 16: CBP outlet; 17: 4th feedwater heat exchanger outlet).

\subsection{Responses to step changes in coal load and control tuning}

As discussed earlier, PID controllers were used to regulate the power system and maintain controlled variables at their set points. The proportional term $\left(K_{p}\right)$, integral $\left(K_{i}\right)$, and derivative term $\left(K_{d}\right)$ of each controller were tuned using the plant model, following standard methods [43, 44, 55. Specifically, the parameters of all the PID controllers, $K_{i}$ and $K_{d}$ were first set to zero and then the value of $K_{p}$ was increased until the output signal started oscillating. $K_{p}$ was set to approximately half of that value for a quarter amplitude decay of signal. $K_{i}$ was tuned by increasing its value until the signal started oscillating around its set point. Then, $K_{d}$ was increased until the output signal reached and maintained the desired set point in an acceptably short period of time. Table 5 reports the resulting tuning parameters of all the PID controllers incorporated 
in the power plant model, $K_{p}, K_{i}$, and $K_{d}$. The control set points, minimum and maximum outputs, and initial signal output for each controller, reported in Table 5, were specified according to the literature [40, 42, 48, 55].

Table 5: Model parameters of PID controllers.*

\begin{tabular}{|l|l|l|l|l|l|}
\hline Parameters & PID 1 & PID 2 & PID 3 & PID 4 & PID 5 \\
\hline \hline $\begin{array}{l}\text { Controlled } \\
\text { variables }\end{array}$ & $\begin{array}{l}\text { Drum } \\
\text { level }\end{array}$ & $\begin{array}{l}T_{\text {SH }} \text { con- } \\
\text { troller }\end{array}$ & Excess $\mathrm{O}_{2}$ & $\begin{array}{l}\text { Condenser } \\
\text { level }\end{array}$ & $\begin{array}{l}\text { Deaerator } \\
\text { level }\end{array}$ \\
\hline $\begin{array}{l}\text { Manipulated } \\
\text { variables }\end{array}$ & $\begin{array}{l}\text { BFP } \\
\text { speed }\end{array}$ & $\begin{array}{l}\text { Valve } \\
\text { opening }\end{array}$ & $\dot{m}_{A i r}$ & CP speed & $\begin{array}{l}\text { CBP } \\
\text { speed }\end{array}$ \\
\hline Set point & $0 \mathrm{~m}$ & $385^{\circ} \mathrm{C}$ & $3 \%$ & $0.4 \mathrm{~m}$ & $0 \mathrm{~m}$ \\
\hline$K_{p}$ & 0.8 & -0.2 & -0.1 & -4.5 & -4.5 \\
\hline$K_{i}$ & 0.005 & 0.01 & 0.01 & 0.005 & 0.005 \\
\hline$K_{d}$ & 0.01 & 0.01 & 0.0025 & 0.0025 & 0.0025 \\
\hline Max output & 1.5 & 1 & 1.5 & 1.5 & 1.5 \\
\hline Min output & 0.5 & 0.000001 & 0.5 & 0.5 & 0.5 \\
\hline Initial output & 0 & 0.000001 & 1 & 1 & 1 \\
\hline
\end{tabular}

* BFP: Boiler feed pump; CP: Condensate pump; CBP: Condensate booster pump.

For the purpose of analyzing the reliability and stability of the power plant simulator, we estimated its performance in closed-loop operation in response to $5 \%,-10 \%$ and $-15 \%$ step changes in coal load (the model was originally developed and validated for full load). The set points of controlled variables, $T_{\mathrm{SH}}$, liquid level of Drum, liquid level of condenser and liquid level of the deaerator, and different coal loads are provided in Table 6 .

Table 6: Set points of controlled variables and coal loads.

\begin{tabular}{|l|l||l|l|}
\hline Controlled variable & Set point & Coal load & Coal flow $[\mathrm{kg} / \mathrm{s}]$ \\
\hline \hline Drum level $[\mathrm{m}]$ & 0 & $100 \%$ & 56.38 \\
\hline$T_{\mathrm{SH}}\left[{ }^{\circ} \mathrm{C}\right]$ & 538 & $95 \%$ & 53.56 \\
\hline Condenser level $[\mathrm{m}]$ & 0.4 & $90 \%$ & 50.74 \\
\hline Deaerator level $[\mathrm{m}]$ & 0 & $85 \%$ & 47.92 \\
\hline
\end{tabular}


Figure 8 presents the response of the controlled variables during different step changes in coal load, specifically the variation of the liquid level of the Drum, $T_{\mathrm{SH}}$, liquid level of the condenser, liquid level of the deaerator, and power generation. The $-5 \%,-10 \%$ and $-15 \%$ step changes in coal load were imposed after $1 \mathrm{hr}$ of simulation and the duration of the change was set to 1 s. The timescale of $1 \mathrm{hr}$ is reasonable and representative of control actions in response to coal load changes in the power plant. It is also used as the time span for supervisory control actions in Part II of this work. 45] The power plant model was first initialized to steady state at full load. As shown in Figure 8 the negative step change in coal flow rate leads to small fluctuations in the controlled variables and a corresponding step change in power generation. For example, in Figure 8(a), the drum level oscillated during the transition to part load operation, but this oscillation was negligible. The controller enables the drum level to return to the set point within minutes. Specifically, the drum level reached steady state in $10 \mathrm{~min}, 17 \mathrm{~min}$ and $20 \mathrm{~min}$ after $-5 \%,-10 \%$ and $-15 \%$ step changes in coal load, respectively. Figure $8(\mathrm{~d})$ shows the corresponding power generation for the three different coal load operations, as well as their temporal responses. The power generations was $577 \mathrm{MW}, 548 \mathrm{MW}$ and 519 MW at 95\%, 90\% and 85\% coal loads, respectively. The controller tuning was robust for the condenser and deaereator levels with rapid responses and small oscillations. In summary, the model responses to step changes in the coal load illustrate the robustness of the controllers, and the value of the dynamic model of the power plant in tuning the controllers to maintain the regulated variables at set point, even for sudden (and somewhat unrealistic) changes in coal load. This power plant model, validated quantitatively at steady state and qualitatively in terms of closed-loop dynamic performance, can be used as a robust test bed for dynamic simulation and optimization of power plants, which is the focus of Part II of this series [45]. 


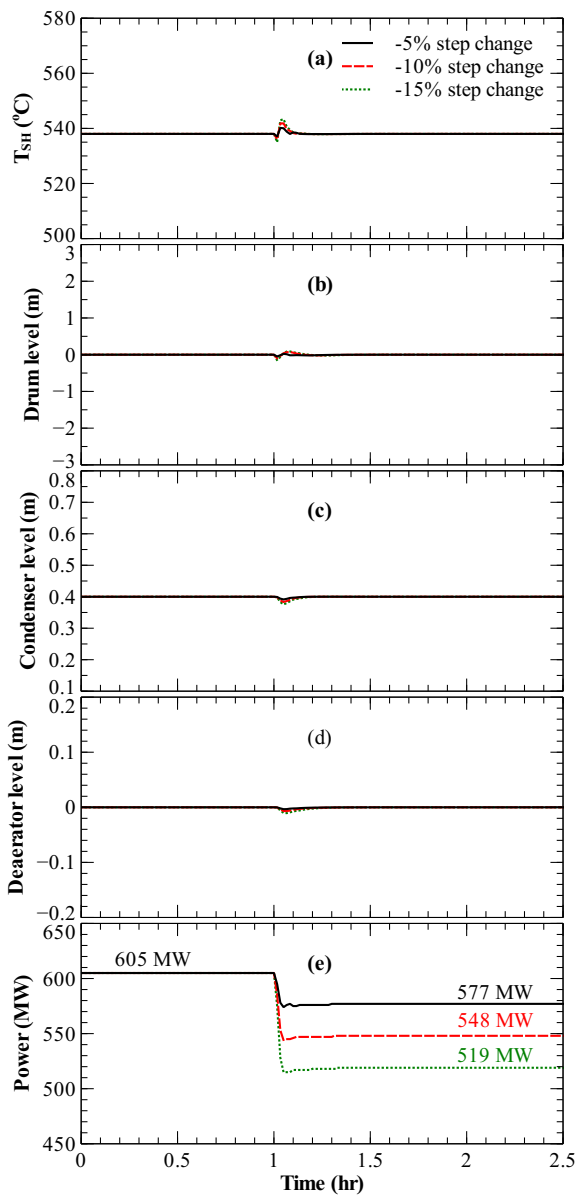

Figure 8: Response of the power plant model with control design to $-5 \%,-10 \%$ and $-15 \%$ step changes in coal load, in terms of (a) $T_{\mathrm{SH}}$, (b) the liquid level of the Drum, (c) the liquid level of the condenser, (d) the liquid level of the deaerator and (e) power generation. 


\section{Conclusions}

380 power plant model, with reheat and regenerative cycles. The simulation results of the power plant operating at full load were in excellent agreement with data from a reference power plant. The steps for designing and tuning a regulatory control architecture for this power plant were presented in detail. The stability

We presented the development of a $605 \mathrm{MW}$ coal-fueled subcritical pressure and flexibility of the studied power plant were analyzed with dynamic simulations, performed in response to $-5 \%,-10 \%$ and $-15 \%$ step changes in coal load. The plant model exhibited fast responses to these sudden changes in coal load, showing that the regulatory control scheme was tuned to reliably and robustly keep the controlled variables at their set points and the integrated plant safe and operational. Overall, the system-level model of the power plant with its regulatory control scheme embedded in the model is a robust test bed for dynamic simulation and optimization. In Part II of this work, we focus on the dynamic modeling of power plants in response to time-varying power demand, and the design of a supervisory controller for optimization of the net plant efficiency, with parallel reduction of coal consumption and $\mathrm{CO}_{2}$ footprint. The model (de-

veloped in the equation-oriented environment of Modelica) is available free of charge as a Supporting Information to this paper.

\section{Acknowledgments}

This material is based upon work supported by the National Science Foundation under Grant No. 1054718. CC and ZZ gratefully acknowledge financial support, helpful advice and guidance from Alstom Power. This work was partially sponsored by the United Technologies Corporation Institute for Advanced Systems Engineering (UTC-IASE) of the University of Connecticut. Any opinions expressed herein are those of the authors and do not represent those of the sponsor. 


\section{Appendix: Parameters and fluid media properties used in the power plant model}

As mentioned in the main text of this manuscript, the power plant model was developed in the simulation environment of Dymola [4] using the Modelica necessary to reproduce the model developed. The two phase medium and gas medium used in the Dymola model were the WaterIF97 of the Modelon library and the ExhaustWithAsh medium of the ThermalPower library, respectively. The air medium had nominal mass composition of $1.3 \%$ Ar, $75 \% \mathrm{~N}_{2}, 23 \% \mathrm{O}_{2}$ default values if not otherwise specified in this section. For the heat exchangers in the boiler, the heat transfer type was set to "Gas side heat transfer over bundles" in the primary (prim) channel with the ExhaustWithAsh medium, and the "Constant overall transfer coefficient" model $(\alpha)$ was used for the secondary ${ }_{425}$ (sec) channel with the WaterIF97 medium. In the Evaporator, the radiationinclusive heat transfer model was used with a total effective heat transfer area of $3023 \mathrm{~m}^{2}$ and enhancement factor of 0.12 . Table A1 shows the model parameters of the heat exchangers in the boiler. The medium in the steam side subsystem was the WaterIF97 Modelica medium. In the water preheaters, the vapor was 430 set to flow through the primary channel and the liquid phase water through the secondary channel. Table A2 shows the parameters of water preheaters in the steam side. Tables A3 and A4 present the parameters of the steam turbines and pumps, respectively. 
Table A1: Model parameters of the heat exchangers in the boiler.

\begin{tabular}{|c|c|c|c|c|}
\hline Parameters & Economizer & Evaporator & Superheater & Reheater \\
\hline \multicolumn{5}{|c|}{ Geometry } \\
\hline Length [m] & 5 & 4.5 & 5 & 5 \\
\hline Width $[\mathrm{m}]$ & 5 & 4.5 & 5 & 5 \\
\hline Height $[\mathrm{m}]$ & 3.5 & 3.5 & 3.5 & 3.5 \\
\hline Tubes/row & 199 & 160 & 199 & 199 \\
\hline Passes & 120 & 160 & 120 & 120 \\
\hline \multicolumn{5}{|c|}{ Initialization } \\
\hline$T_{\text {prim,in }}[\mathrm{bar}]$ & 718 & 1963 & 1582 & 985 \\
\hline$T_{\text {prim,out }}[\mathrm{bar}]$ & 327 & 1582 & 985 & 718 \\
\hline$P_{\text {sec,in }}\left[{ }^{\circ} \mathrm{C}\right]$ & 199 & 184 & 182 & 45 \\
\hline$P_{\text {sec,out }}\left[{ }^{\circ} \mathrm{C}\right]$ & 182 & 182 & 173.7 & 40.5 \\
\hline \multicolumn{5}{|c|}{ Correlations } \\
\hline$\triangle P_{\mathrm{sec}}[\mathrm{bar}]$ & 14.5 & 1.2 & 6.2 & 4.5 \\
\hline$\alpha\left[\mathrm{W} /\left(\mathrm{m}^{2} \cdot \mathrm{K}\right)\right]$ & 1275 & 72 & 158 & 158 \\
\hline
\end{tabular}


Table A2: Model parameters of the water preheaters in the steam side.

\begin{tabular}{|c|c|c|c|}
\hline Parameters & 1st preheater & 3rd preheater & 4th preheater \\
\hline \multicolumn{4}{|c|}{ Geometry } \\
\hline Plates & 1200 & 2600 & 3000 \\
\hline Plate height $[\mathrm{m}]$ & 8 & 8 & 6 \\
\hline \multicolumn{4}{|c|}{ Streams } \\
\hline$\alpha_{\text {prim }}\left[\mathrm{W} /\left(\mathrm{m}^{2} \cdot \mathrm{K}\right)\right]$ & 3500 & 1200 & 2170 \\
\hline$\triangle P_{\text {prim }}[\mathrm{bar}]$ & 1.292 & 0.2 & 0.1 \\
\hline$P_{\text {prim,in }}[\mathrm{bar}]$ & 1.36 & 12.7 & 25.2 \\
\hline$\dot{m}_{\text {prim }}[\mathrm{kg} / \mathrm{s}]$ & 27 & 50 & 30 \\
\hline$H_{\text {prim,in }}[\mathrm{kJ} / \mathrm{kg}]$ & 2755 & 680 & 3300 \\
\hline$H_{\text {prim,out }}[\mathrm{kJ} / \mathrm{kg}]$ & 381 & 500 & 747 \\
\hline$\alpha_{\mathrm{sec}}\left[\mathrm{W} /\left(\mathrm{m}^{2} \cdot \mathrm{K}\right)\right]$ & 3500 & 6000 & 15000 \\
\hline$\triangle P_{\mathrm{sec}}[\mathrm{bar}]$ & 0.01 & 0.2 & 0.2 \\
\hline$P_{\text {prim,in }}[\mathrm{bar}]$ & 4.4 & 12.4 & 12.2 \\
\hline$\dot{m}_{\mathrm{sec}}[\mathrm{kg} / \mathrm{s}]$ & 30 & 515 & 515 \\
\hline$H_{\mathrm{sec}, \mathrm{in}}[\mathrm{kJ} / \mathrm{kg}]$ & 148 & 572 & 600 \\
\hline$H_{\text {sec,out }}[\mathrm{kJ} / \mathrm{kg}]$ & 381 & 738 & 625 \\
\hline
\end{tabular}

Table A3: Model parameters of the steam turbines in the steam side.

\begin{tabular}{|l|l|l|l|l|l|l|}
\hline Parameters & HP & IP1 & IP2 & LP1 & LP2 & LP3 \\
\hline \hline$\dot{m}$ & 514 & 514 & 484.4 & 455.1 & 430.1 & 382.9 \\
\hline$\eta_{\text {isentropic }}$ & 0.85 & 0.92 & 0.855 & 0.883 & 0.8 & 0.88 \\
\hline$P_{\text {in }}[\mathrm{bar}]$ & 173.7 & 40.5 & 25.2 & 12.7 & 4.8 & 1.2 \\
\hline$P_{\text {out }}[\mathrm{bar}]$ & 45 & 25.2 & 12.7 & 4.8 & 1.2 & 0.068 \\
\hline$H_{\text {in }}[\mathrm{kJ} / \mathrm{kg}]$ & 3391 & 3550 & 3393 & 3212 & 2985 & 2720 \\
\hline$H_{\text {out }}[\mathrm{kJ} / \mathrm{kg}]$ & 3063 & 3394 & 3212 & 2985 & 2730 & 2480 \\
\hline
\end{tabular}


Table A4: Model parameters of the pumps in the steam side.

\begin{tabular}{|l|l|l|l|}
\hline Parameters & CP & CBP & BFP \\
\hline \hline Volume $\left[\mathrm{m}^{3}\right]$ & 0.1 & 0.1 & 001 \\
\hline Flow rate $\left[\mathrm{m}^{3} / \mathrm{s}\right]$ & 0.4298 & 0.593 & 0.629 \\
\hline$\dot{m}[\mathrm{~kg} / \mathrm{s}]$ & 429.8 & 513.9 & 514 \\
\hline$P_{\text {in }}[\mathrm{bar}]$ & 0.16 & 3.31 & 12 \\
\hline$P_{\text {in }}[\mathrm{bar}]$ & 3.31 & 12.4 & 199 \\
\hline$H_{\text {in }}[\mathrm{kJ} / \mathrm{kg}]$ & 142 & 625 & 800 \\
\hline
\end{tabular}

The control tuning was based on standard control tuning methods [43, 44] of PID controllers discussed in the literature 55. Here, the tuning for the drum level controller is used as an example of the control tuning excessive. Table A5 provides the values of $K_{p}, K_{i}$, and $K_{d}$ before and after the tuning.

Table A5: $K_{p}, K_{i}$, and $K_{d}$ for Drum level controller tuning.

\begin{tabular}{|l|l|l|}
\hline Parameters & Pre-tuning & Post-tuning \\
\hline \hline$K_{p}$ & 0.5 & 0.8 \\
\hline$K_{i}$ & 0.05 & 0.005 \\
\hline$K_{d}$ & 0.1 & 0.01 \\
\hline
\end{tabular}

Figure A1 shows the temporal profile (including initialization) of the level of water in the Drum with the controller before and after tuning. The drum level controller was tuned to enable the controlled variable to reach set point without oscillations and rapidly. This was achieved by increasing $K_{p}$ from 0.5 to 0.8 , and decreasing $K_{i}$ and $K_{d}$ from 0.05 to 0.005 , and 0.1 to 0.01 , respectively. 


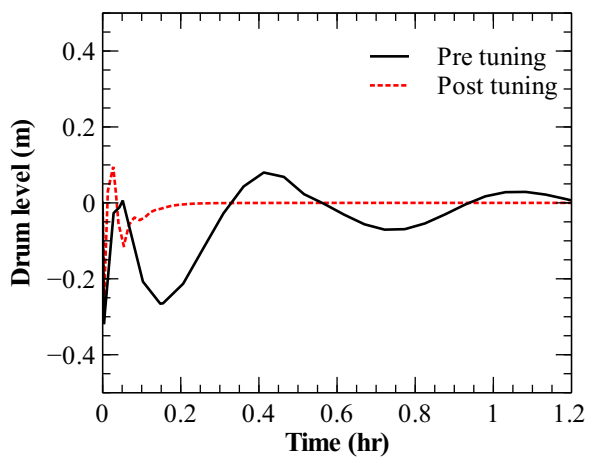

Figure A1: Drum level controller tuning. 


\section{References}

q [1] U.S. Energy Information Administration, Energy Information Administration: Annual Energy Outlook (2016).

URL http://www.eia.gov/forecasts/aeo/

\[2] R. E. H. Sims, H.-h. Rogner, K. Gregory, Carbon emission and mit-

घ. igation cost comparisons between fossil fuel, nuclear and renewable energy resources for electricity generation 31 (0301) (2003) 1315-1326. doi:http://dx.doi.org/10.1016/S0301-4215(02)00192-1. URL http://www.sciencedirect.com/science/article/pii/ S0301421502001921

¿ [3] G. Sáenz de Miera, P. del Río González, I. Vizcaíno, Analysing the

a impact of renewable electricity support schemes on power prices: The 455 case of wind electricity in Spain, Energy Policy 36 (9) (2008) 3345-3359. doi:10.1016/j.enpol.2008.04.022

a URL http://linkinghub.elsevier.com/retrieve/pii/ S0301421508001882

口[4] A. Kribus, R. Zaibel, D. Carey, A. Segal, J. Karni, A solar-driven combined cycle power plant, Solar Energy 62 (2) (1998) 121-129. doi:10.1016/S0038-092X(97)00107-2.

a URL http://linkinghub.elsevier.com/retrieve/pii/ S0038092X97001072

q [5] E. Hughes, Biomass cofiring: economics , policy and opportuni465 ties, Biomass \& Bioenergy 19 (July) (2000) 457-465. doi:http: //dx.doi.org/10.1016/S0961-9534(00)00057-X.

1 URL http://www.sciencedirect.com/science/article/pii/ S096195340000057X

a [6] G. C. Bakos, Feasibility study of a hybrid wind/hydro power-system for 470 low-cost electricity production Applied Energy 72 (3-4) (2002) 599-608. 


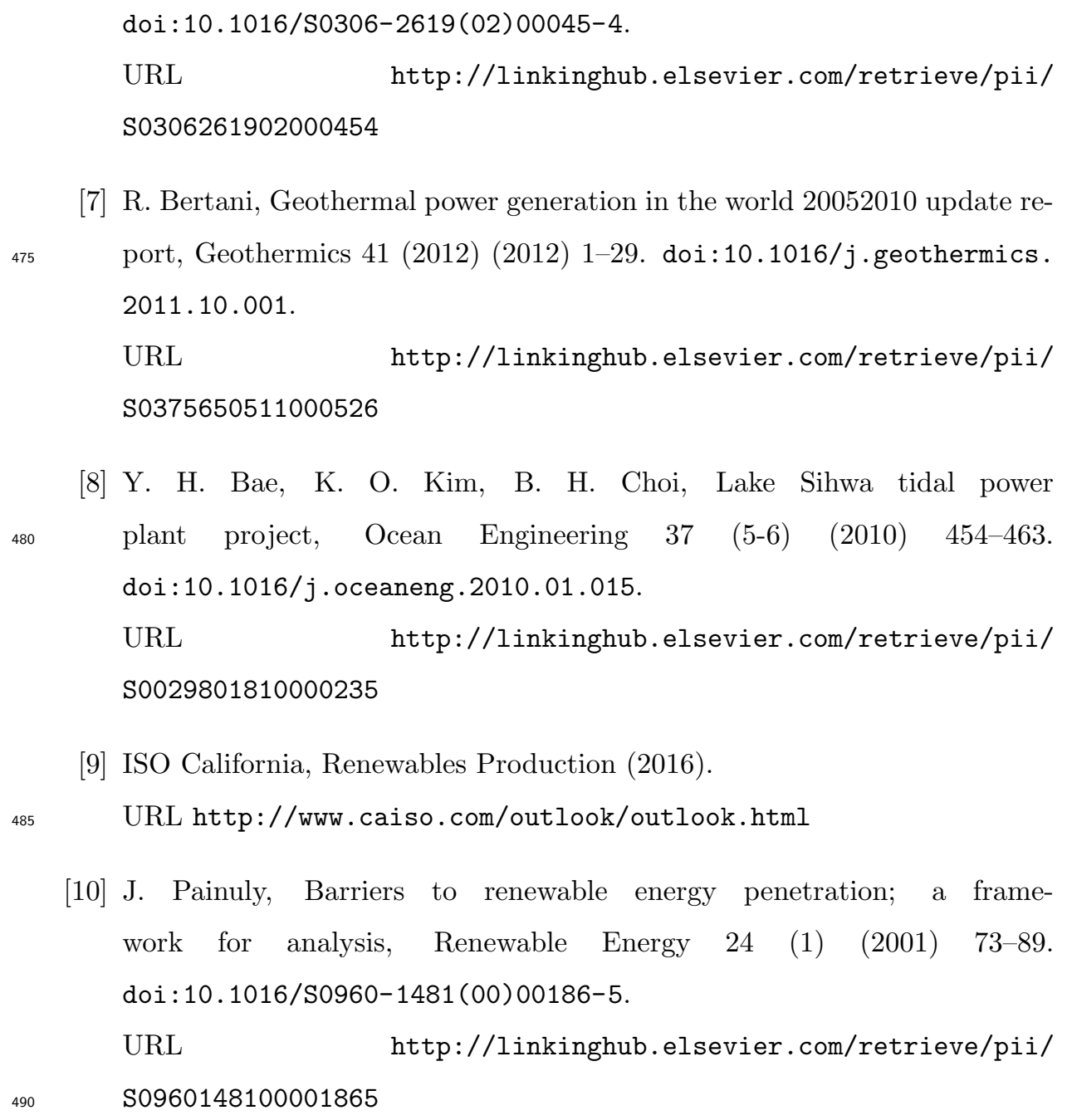

n [7] R. Bertani, Geothermal power generation in the world 20052010 update re-

475 port, Geothermics 41 (2012) (2012) 1-29. doi:10.1016/j.geothermics. 2011.10 .001 URL http://linkinghub.elsevier.com/retrieve/pii/ S0375650511000526

q [8] Y. H. Bae, K. O. Kim, B. H. Choi, Lake Sihwa tidal power 480 plant project, Ocean Engineering $37 \quad(5-6) \quad$ (2010) 454-463. doi:10.1016/j.oceaneng.2010.01.015.

口 URL http://linkinghub.elsevier.com/retrieve/pii/ S0029801810000235

[9] ISO California, Renewables Production (2016). URL http://www.caiso.com/outlook/outlook.html

[10] J. Painuly, Barriers to renewable energy penetration; a framework for analysis, Renewable Energy 24 (1) (2001) 73-89. doi:10.1016/S0960-1481(00)00186-5.

(1) URL http://linkinghub.elsevier.com/retrieve/pii/ S0960148100001865

[11] R. Edmunds, L. Davies, P. Deane, M. Pourkashanian, Thermal power

n plant operating regimes in future British power systems with increasing variable renewable penetration, Energy Conversion and Management 105 (2015) 977-985. doi:10.1016/j.enconman.2015.08.067 S0196890415008213

[12] Y. Wang, V. Silva, M. Lopez-Botet-Zulueta, Impact of high penetration a of variable renewable generation on frequency dynamics in the continental 
Europe interconnected system, IET Renewable Power Generation 10 (1)

[13] P. Eser, A. Singh, N. Chokani, R. S. Abhari, Effect of increased renewables generation on operation of thermal power plants, Applied Energy 164

[14] X. Pei, B. He, L. Yan, C. Wang, W. Song, J. Song, Process simulation of

n. oxy-fuel combustion for a 300MW pulverized coal-fired power plant using

[15] A. Z. Sahin, A. Al-Sharafi, B. S. Yilbas, A. Khaliq, Overall perfor515

口.
doi:10.1016/j.enconman.2016.09.080.

a URL http://linkinghub.elsevier.com/retrieve/pii/ $525 \quad$ S0196890416308792

[17] S. Peng, Z. Wang, H. Hong, D. Xu, H. Jin, Exergy evaluaa. tion of a typical 330MW solar-hybrid coal-fired power plant in 
China, Energy Conversion and Management 85 (2014) 848-855.

doi:10.1016/j.enconman.2013.12.073.

URL http://linkinghub.elsevier.com/retrieve/pii/

S0196890414000478

[18] L. Zhou, G. Xu, S. Zhao, C. Xu, Y. Yang, Parametric analysis and pro-

1 cess optimization of steam cycle in double reheat ultra-supercritical power plants, Applied Thermal Engineering 99 (2016) 652-660. doi:10.1016/j.applthermaleng.2016.01.047. URL http://linkinghub.elsevier.com/retrieve/pii/ S1359431116001022

[19] P. R. Kumar, V. R. Raju, N. R. Kumar, Simulation and parametric optimisation of thermal power plant cycles, Perspectives in Science (2016) $3-5$ doi:10.1016/j.pisc.2016.04.060. URL http://linkinghub.elsevier.com/retrieve/pii/ S2213020916300829

[20] E. Kakaras, A. Koumanakos, A. Doukelis, D. Giannakopoulos, I. Vorrias, Oxyfuel boiler design in a lignite-fired power plant, Fuel 86 (14) (2007) 2144-2150. doi:10.1016/j.fuel.2007.03.037.

口 URL http://linkinghub.elsevier.com/retrieve/pii/ S0016236107001500

[21] P. Colonna, H. van Putten, Dynamic modeling of steam power cycles. Part I - Modeling paradigm and validation, Applied Thermal Engineering 27 (2-3) (2007) 467-480. doi:10.1016/j.applthermaleng.2006.06.011 URL http://linkinghub.elsevier.com/retrieve/pii/ S1359431106002389

[22] H. van Putten, P. Colonna, Dynamic modeling of steam power a cycles: Part II Simulation of a small simple Rankine cycle sys555 tem Applied Thermal Engineering 27 (14-15) (2007) 2566-2582. doi:10.1016/j.applthermaleng.2007.01.035. 
URL http://linkinghub.elsevier.com/retrieve/pii/ S135943110700066X

[23] F. Casella, P. Colonna, Dynamic modeling of IGCC power 560 plants, Applied Thermal Engineering 35 (2012) 91-111. doi: 10.1016/j.applthermaleng.2011.10.011.

口 URL http://linkinghub.elsevier.com/retrieve/pii/ S1359431111005497

[24] F. Casella, T. Mathijssen, P. Colonna, J. V. Buijtenen, J. van Buijtenen, Dynamic Modeling of Organic Rankine Cycle Power Systems, Journal of Engineering for Gas Turbines and Power 135 (4) (2013) 042310. doi:10.1115/1.4023120.

URL http://gasturbinespower.asmedigitalcollection.asme.org/ article.aspx?doi=10.1115/1.4023120

570 25] Modelica Association, Modelica - A Unified Object-Oriented Language for Physical Systems Modeling (2010).

URL https://modelica.org/documents/ModelicaSpec33. pdfcaSpec32.pdf

[26] F. Casella, A. Leva, Modelica open library for power plant simulation: 575 design and experimental validation in: Proceeding of the 2003 Modelica conference, Linköping, Sweden, 2003.

口 URL https://www.modelica.org/events/Conference2003/papers/ h08_Leva.pdf

[27] C. Chen, L. Han, G. M. Bollas, Dynamic Simulation of Fixed-Bed Chemical-Looping Combustion Reactors Integrated in Combined Cycle

1. Power Plants, Energy Technology 4 (7) (2016) 1209-1220. doi:10.1002/ ente.201600079.

URL http://doi.wiley.com/10.1002/ente.201600079

[28] L. Wang, Y. Yang, C. Dong, T. Morosuk, G. Tsatsaronis, Parametric 585 optimization of supercritical coal-fired power plants by MINLP and 
differential evolution, Energy Conversion and Management 85 (2014)

828-838. doi:10.1016/j.enconman.2014.01.006.

प

URL http://linkinghub.elsevier.com/retrieve/pii/

S0196890414000491

${ }_{590}^{0}[29]$ K. S. Bhambare, S. K. Mitra, U. N. Gaitonde, Modeling of a Coal-Fired Natural Circulation Boiler, Journal of Energy Resources Technology 129 (2) (2007) 159. doi:10.1115/1.2719209.

口 URL http://energyresources.asmedigitalcollection.asme.org/ article.aspx?articleid=1414694

[30] R. Starkloff, F. Alobaid, K. Karner, B. Epple, M. Schmitz, F. Boehm,

1. Development and validation of a dynamic simulation model for a large coal-fired power plant, Applied Thermal Engineering 91 (2015) 496-506. doi:10.1016/j.applthermaleng.2015.08.015.

URL http://linkinghub.elsevier.com/retrieve/pii/

600 S1359431115008108

[31] R. Franke, B. Babji, M. Antoine, A. Isaksson, Model-based online applications in the ABB Dynamic Optimization framework, in: Proceedings of the 6th International Modelica Conference, 2008, pp. 279-285.

[32] D. Bouskela, G. Lebreton, C. Cedex, B. E. Hefni, Dynamic modelling of a combined cycle power plant with ThermoSysPro, in: Modelica 2011 conference proceedings, 2011, pp. 365-375.

1 URL http://scholar.google.com/scholar?hl=en $\{\&\}$ btnG=

1] Search\{\&\}q=intitle:Dynamic+modelling+of+a+combined+cycle+

power+plant+with+ThermoSysPro\{\#\}0

[33] K. Dietl, S. Gallardo Yances, A. Johnsson, J. Å kesson, K. Link, S. Ve-

a lut, Industrial application of optimization with Modelica and Optimica using intelligent Python scripting, in: Proceedings of the 10th Interna-

घ tional Modelica Conference, Lund, Sweden, 2014, pp. 777-786. doi: 10.3384/ecp14096777. 
URL http://www.ep.liu.se/ecp_article/index.en.aspx?issue=96; article $=81$

[34] Y. Wang, D. Hill, R. Middleton, L. Gao, Transient stability enhancement and voltage regulation of power systems, IEEE Transactions on Power Systems 8 (2) (1993) 620-627. doi:10.1109/59.260819

[35] C. T. Pan, C. M. Liaw, An adaptive controller for power system loadfrequency control IEEE Transactions on Power Systems 4 (1) (1989) 122-128. doi:10.1109/59.32469. URL http://ieeexplore.ieee.org/lpdocs/epic03/wrapper.htm? arnumber $=32469$

[36] A. Ben-Abdennour, R. Edwards, K. Lee, LQG/LTR robust control of nuclear Reactors with improved temperature performance, IEEE Transactions on Nuclear Science 39 (6) (1992) 2286-2294. doi:10.1109/23.211438.

1 URL http://ieeexplore.ieee.org/lpdocs/epic03/wrapper.htm? arnumber $=211438$

[37] F. Alobaid, R. Starkloff, S. Pfeiffer, K. Karner, B. Epple, H.-G. Kim,

1 A comparative study of different dynamic process simulation codes for combined cycle power plants Part A: Part loads and off-design operation, Fuel 153 (2015) 692-706. doi:10.1016/j.fuel.2015.02.010.

635 URL http://linkinghub.elsevier.com/retrieve/pii/ S0016236115001507

[38] F. Alobaid, R. Starkloff, S. Pfeiffer, K. Karner, B. Epple, H.-G. Kim,

a A comparative study of different dynamic process simulation codes for combined cycle power plants Part B: Start-up procedure, Fuel 153 (2015)

640 707-716. doi:10.1016/j.fuel.2015.02.011.

口 URL http://linkinghub.elsevier.com/retrieve/pii/ S0016236115001520 
[39] F. Alobaid, N. Mertens, R. Starkloff, T. Lanz, C. Heinze, B. Epple, Progress in dynamic simulation of thermal power plants, Progress in Energy and Combustion Science 59 (2016) 79-162. doi:http://dx.doi.org/10.1016/ j.pecs.2016.11.001.

URL http://dx.doi.org/10.1016/j.pecs .2016.11.001

[40] J. G. Singer (Ed.), Combustion Fossil Power: A Reference Book on Fuel Burning and Steam Generation, 4th Edition, Combustion Engineering, Windsor, Connecticut, 1991.

[41] J. Russell, Steam \& Disel Power Plant Operators Examinations, 3rd Edition, J. R. Publishing, 2000.

[42] S. Teir, A. Kulla, Steam Boiler Technology eBook, Energy Engineering and Environmental Protection Publications, Espoo, 2002.

655 [43] E. Oko, M. Wang, Dynamic modelling, validation and analysis of coal-fired subcritical power plant, Fuel 135 (2014) 292-300. doi:10.1016/j.fuel.2014.06.055 URL http://linkinghub.elsevier.com/retrieve/pii/ S0016236114006218

[44] C. Schuhbauer, M. Angerer, H. Spliethoff, F. Kluger, H. Tschaffon, Coupled simulation of a tangentially hard coal fired 700C boiler, Fuel 122 (2014) 149-163. doi:10.1016/j.fuel.2014.01.032. URL http://linkinghub.elsevier.com/retrieve/pii/ S0016236114000428

${ }_{665}$ [45] C. Chen, G. M. Bollas, Dynamic Modeling, Simulation and Optimization of a Subcritical Steam Power Plant. Part II: Dynamic Optimization under Time-Varying Power Load, Energy Conversion and Management.

[46] T. Wall, Y. Liu, C. Spero, L. Elliott, S. Khare, R. Rathnam, F. Zeenathal, B. Moghtaderi, B. Buhre, C. Sheng, R. Gupta, T. Yamada, K. Makino, $670 \quad \square$ J. Yu, An overview on oxyfuel coal combustionState of the art research 
and technology development, Chemical Engineering Research and Design 87 (8) (2009) 1003-1016. doi:10.1016/j.cherd.2009.02.005

[47] H. Elmqvist, D. Brück, M. Otter, Dymola Users Manual (1996).

[48] R. Kehlhofer, B. Rukes, F. Hannemann, F. Stirnimann, Thermal Power Plant Performance Analysis, 3rd Edition, Springer Series in Reliability Engineering, Springer London, London, 2012. doi:10.1007/ 978-1-4471-2309-5. URL http://link. springer.com/10.1007/978-1-4471-2309-5

[49] D. Hasler, W. Rosenquist, R. Gaikwad, New Coal-fired Power Plant Performance and Cost Estimates, Tech. rep. (2009).

口 URL https://www.epa.gov/airmarkets/ new-coal-fired-power-plant-performance-and-cost-estimates

[50] A. Fink, Engineering the First Steam-Ready Industrial Watertube Boiler, Tech. rep.

a URL http://www.cleaverbrooks.com/Reference-Center/

(1) Resource-Library/Whitepapers/Engineering-the-First-Steam-Ready-Industrial-Watertube-Boi aspx

[51] Siemens Power Generation, BENSON Boilers for Maximum CostEffectiveness in Power Plants, Tech. rep. (2014).

URL https://www.energy.siemens.com/hq/
pool/hq/power-generation/power-plants/
steam-power-plant-solutions/bensonboiler/
BENSON\{ \}Boilers\{ \}for\{ \}Maximum\{ \}Cost\{_\}Effectiveness.pdf

[52] Emerson Process Management, Boiler Drum Level Transmitter Calibration, Tech. Rep. October (2010).

1 URL https://www.researchgate.net/file.PostFileLoader. 
html?id=57c06ffa48954c688861daf2\{\&\}assetKey=

[53] S. Londerville, C. E. J. Baukal (Eds.), The Coen \& Hamworthy combustion handbook: fundamentals for power, marine \& industrial applications, CRC Press, 2013.

URL http://www.crcnetbase.com/doi/book/10.1201/b13967

[54] G. M. Masters, Wind Power Systems, in: Renewable and Efficient Electric Power Systems, John Wiley \& Sons, Inc., Hoboken, NJ, USA, 2005, pp. 307-383. doi:10.1002/0471668826.ch6.

URL http://doi.wiley.com/10.1002/0471668826.ch6

[55] K. J. Å ström, T. Hägglund, Advanced PID Control, ISA - The Instrumentation, Systems and Automation Society, 2006.

URL https://lup.lub.lu.se/search/publication/535630 